\title{
House-form and day-lighting: A spatial evaluation of residents' satisfaction in Ogbomoso, Nigeria
}

\author{
Atolagbe A. M. 0. \\ Department of Architecture, Ladoke Akintola University of Technology, Ogbomoso, Nigeria. \\ Accepted 07 May, 2012
}

\begin{abstract}
This study examines the adequacy of natural lighting in the different house forms across the residential zones of Ogbomoso, based on the satisfaction rating of residents. Households from sampled houses across the residential zones of the city were interviewed on their level of satisfaction with natural lighting in their apartments. Comparisons were made between the satisfaction levels in the indigenous, high residential zone (with small windows), and the medium and low, residential density zones of the city (with larger windows), respectively. The result shows that the Brazilian, face-me-l-face-you houses in the medium density zone of the city have better natural lighting than both the compound houses and nuclear family apartments in the high and low residential density zones of the city, respectively.
\end{abstract}

Key words: Natural lighting, house-form, Nigeria, low income, residential zones.

\section{INTRODUCTION}

The decision on the housing technology option for Nigeria is tilting fast in favour of the development of indigenous, alongside imported housing technologies. There can be no better appeal towards this option than the current housing shortage in Nigeria, which is due to residents' reliance on cost intensive foreign housing materials and technology, at the expense of viable, local ones (Matazu, 2011).

Research results abound, proofing the viability of local materials and technology to provide adequate and decent houses to offset the current housing deficit in Nigeria; that was recently put at over $17,000,000$ units (Gana, 2011). These include the efficiency of earth walls for stable, durable and better heat-behaviour (Agarwal, 1981; Chukwuali, 1992; Olateju, 1989); bamboo splint in place of steel for earth reinforcement (Akinmusuru, 1985; Olateju, 1993), and cost reduction potentials in the use of local materials (Olateju, 1989). In spite of these research evidences, there is a sharp dichotomy in the acceptability of local materials and technology among Nigerians aspiring to own houses (Afon, 2006). In an acceptability study conducted in Ogbomoso, only low-income respondents and those who had no other affordable option of owning houses-except through the use of local materials-responded in favour of the latter. And this was only after an intensive enlightenment education on the cost, social and environmental advantages of this option over the conventional, foreign based option (Atolagbe, 1995). The few elitist, medium and high income respondents did not only decline to respond to, or return the questionnaire, but failed to entertain any enlightenment campaign that may alter their disdain for local materials, and consequently, lower their ego in the reckoning of their peers.

Ogbomoso city, the study area, is discernable into three distinct residential zones; the high (indigenous), medium (intermediate) and low, outer density residential zones, corresponding to the pre-colonial, colonial and post-independent settlement zones of the city (Figure 1). The first, high density residential, inner core of the city is characterized by compound housestead, high content of indigenous materials, small sized and few windows, and 


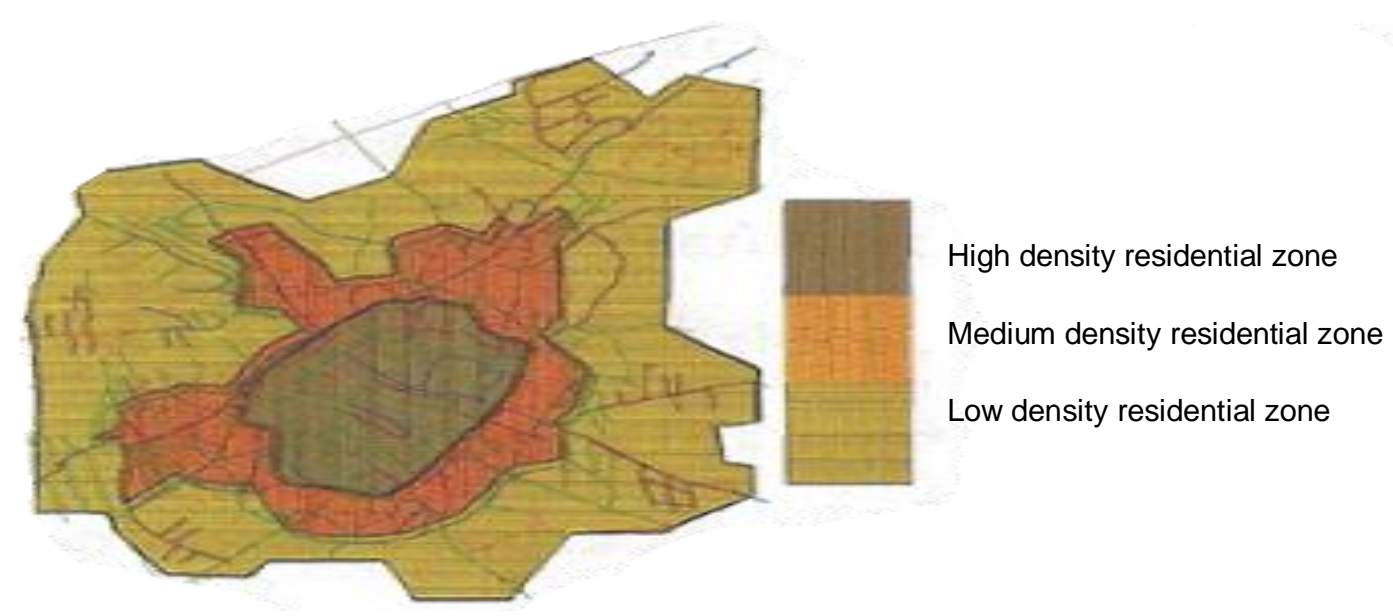

Figure 1. Map of Ogbomoso showing the three residential zones.

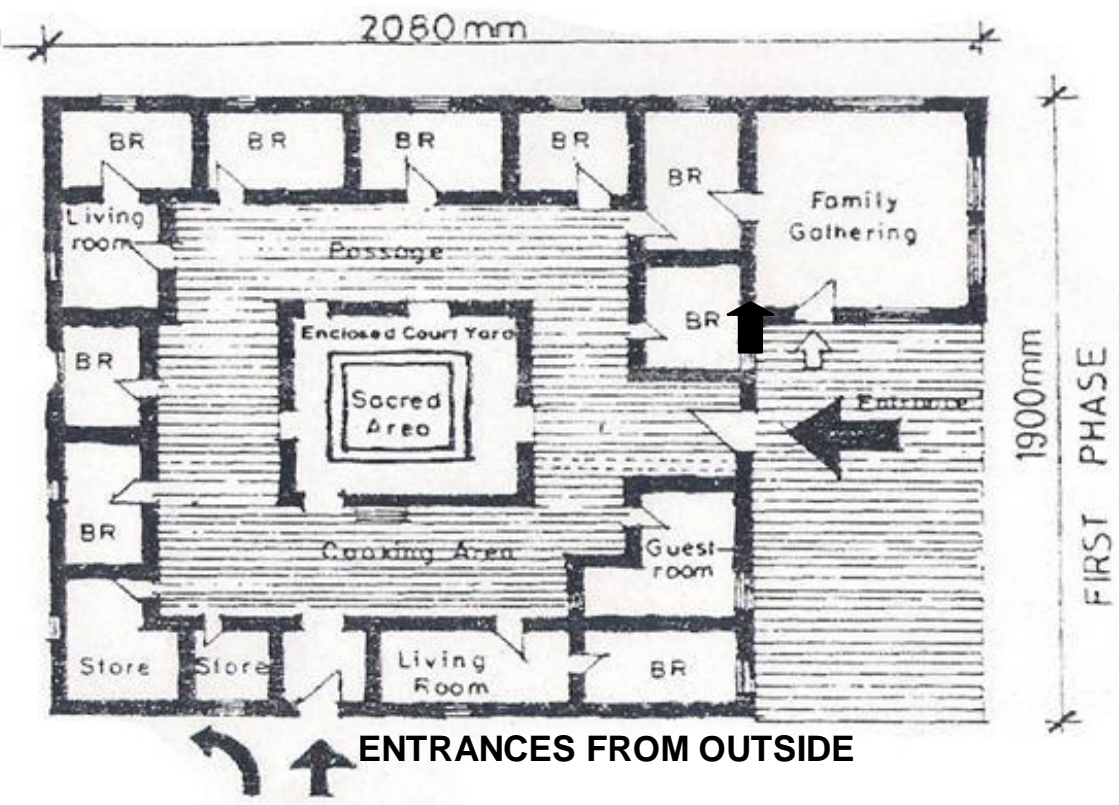

Figure 2i. Housing typology in the high density residential zone.

few interstitial spaces between houses (Figure 2i). The second is the medium density zone, forming a ring around the inner, high residential zone. This zone consists mainly of houses with opposite rows of rooms on either side of a double-banking central hall. Except for the first rooms on either side, forming the sitting/ launching area, most of the other rooms have windows arranged in rows, on the outer side; a room arrangement, which Olorunfemi (1995), described as a barrack house (Figure 2ii). The third zone consists of the low density residential area of the city. Houses in this area are mostly characterized by varying, single family, house-forms; often all-inclusive of toilets, baths, kitchen, etc., with variations in window arrangement and forms (Figure 2iii).
While the height of windows is constant at $1200 \mathrm{~mm}$, their widths are $500,600 \mathrm{~mm}$, and their multiples in the medium and low residential density house forms. In this study, users' satisfaction with the level of natural lighting is examined in houses in these zones against their different sizes, and peculiar forms of window arrangements, respectively. Users' satisfaction may seem a subjective parameter for studying the efficiency, adequacy or acceptability of many phenomena or services. It is not so in the measurement of housing habitability or efficiency in housing infrastructural services. Rather, it is today a new paradigm in determining the quality of habitability in housing methodology. Parameters such as daylight factors, material reflectivity, etc, will in the final analysis 


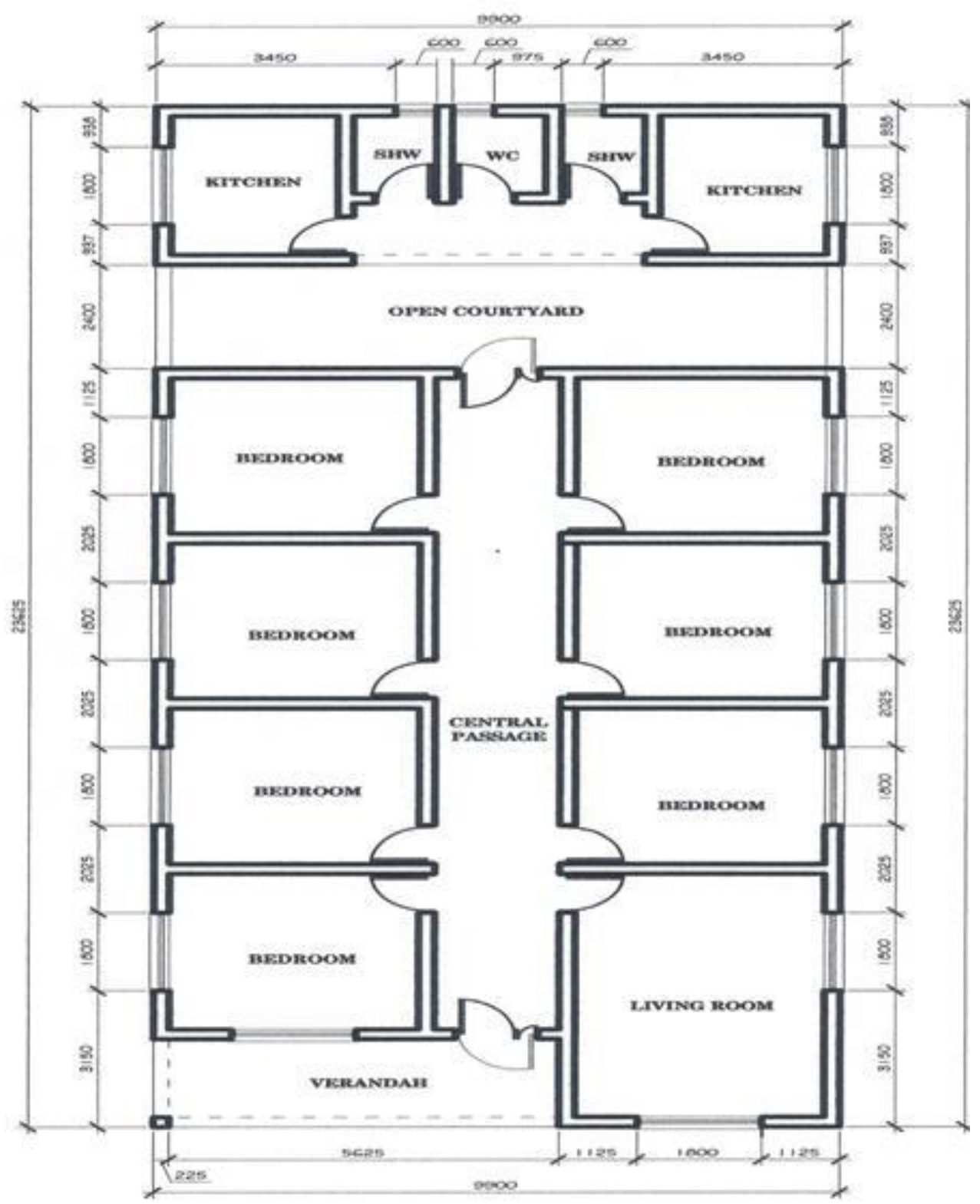

Figure 2ii. Housing typology in the medium density residential zone.

be assessed based on users' living comfort. In other words, users are the reason for the house; their feelings are the most paramount in deciding the quality of a house. Three types (sizes) of windows can be identified in the city; coming also in three forms of arrangement. The first are the small-sized windows; often less than $6000 \mathrm{~mm} \mathrm{X} 600 \mathrm{~mm}$ (height to width) or $0.36 \mathrm{~m}^{2}$ in indigenous, Yoruba compound houses, found in the precolonial settlements in the city (Figure 2i). They are provided at one per room size of $6.42 \mathrm{~m}^{2}$. The second type, common in houses within the intermediate or medium density, colonial, residential zone of the city consists of windows [(500 (w) X 1200 (h)] or [600 (w) X $1200(\mathrm{~h})] \mathrm{mm}$, in double [100 (w) X 1200 (h)] or [1200 (w)
X 1200 (h)]; triple 1500 (w) X 1200 (h) or 1800 (w) X 1200 (h); or more bays each. Other variants of this window module include multiples of 500 (w) X 600 (h) for toilet windows; and 500 (w) X 1200 (h) for other rooms. Height of windows for toilets $(600 \mathrm{~mm})$ and rooms $(1200$ $\mathrm{mm}$ ) are often constant; as only window widths vary. When any variant of this window sizes constitutes about $20 \%$ of the floor area, the optimum for effective daylighting or ventilation is guaranteed. Standard sized windows in this study are thus, those constituting $15-20 \%$ of floor areas of rooms being lighted. Most rooms in this zone face a central corridor/hall (Figure 2ii). Except for the sitting room whose windows are arranged at adjacent walls, windows for bedrooms are arranged along the 


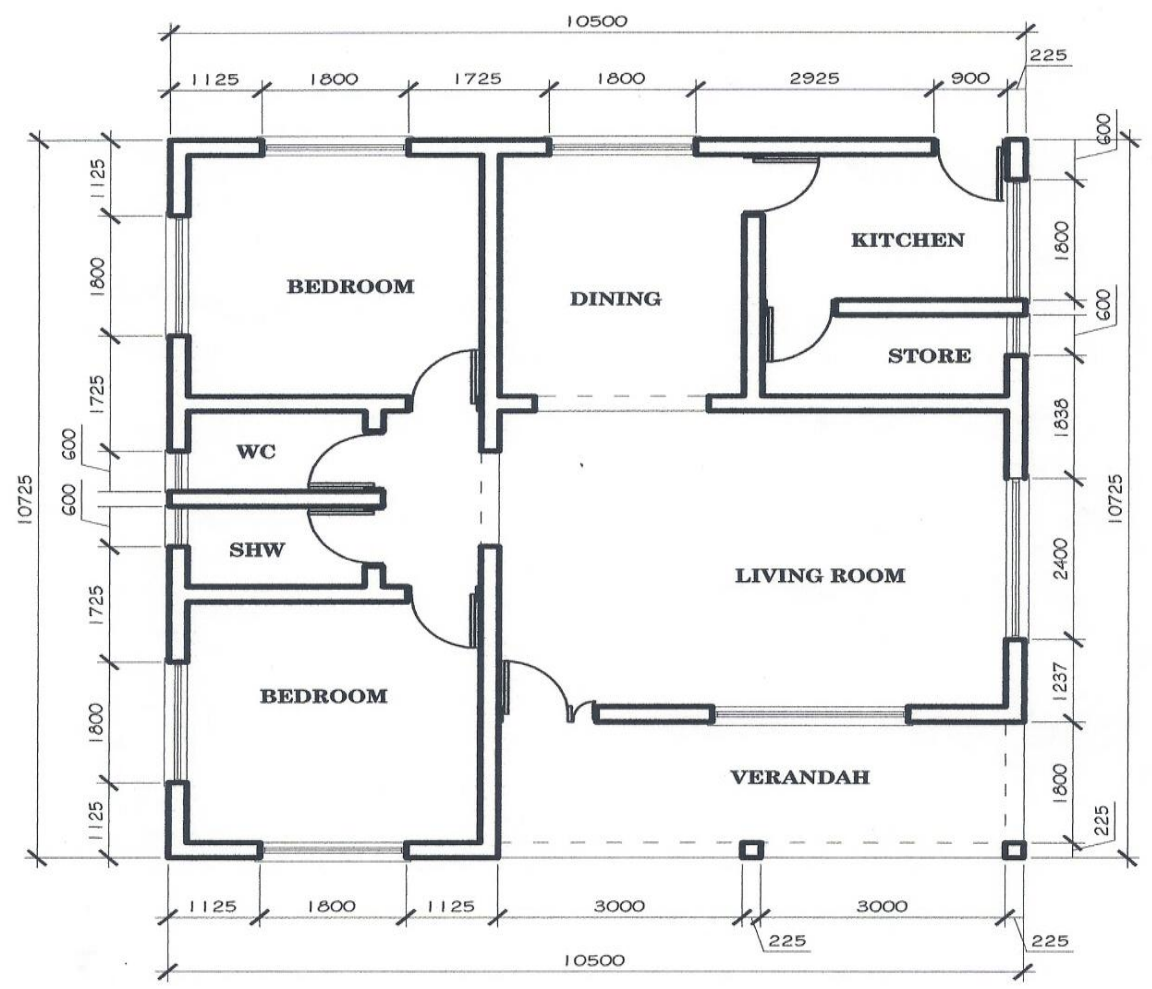

Figure 2iii. Housing typology in the low density residential zone.

outer walls (Figure 2ii). The third window size and arrangement are in houses in the new developing, low density and post independent house-forms in the low density residential zone. Sizes of windows which could range from two to four bays of the standard size are similar to the ones obtainable in the medium density zone. They however have better arrangement; often on adjacent, even opposite walls of the room (Figure 2iii).

Day-lighting in each of these house forms and window arrangements are peculiar to each, but remain virtually constant through the year; as day-lighting does not vary much during the two main (rain and harmattan) seasons in Nigeria. Which of these window sizes and fenestration methods lend to more effective day-lighting (by users' perception), in the city? What features of these houseforms account for such day-lighting differences?

\section{METHODOLOGY}

Using the street map of Ogbomoso, and a multi-stage sampling procedure, about $50 \%$ of the streets were sampled from each residential density type, adding up to 18,15 and 14 streets from the high, medium and low density residential zones, respectively. Next, every fifth house on sampled streets was picked in a randomly, systematic process; also totaling 1247 sampled houses at the rate of 508, 377 and 362 houses, sampled from the high, medium and low density residential zones of the city, respectively (Table 1 ).

A questionnaire consisting of a six-option response, on the satisfaction rating of the houses by household heads was administered in each sampled house on the basis of "first household head available for interview". The options available to the household heads were: No response, very satisfactory, satisfactory, cannot decide, unsatisfactory and very unsatisfactory; according to their level of satisfaction with day-lighting in the apartments they occupy. In an apartment where the head of the first household was not immediately available, the interviewer sought the attention of another household head in the same house.

A contingency table was drawn for the comparison of residents' satisfaction with day-lighting in the three residential zones of the city and a Chi-Square test was carried out to examine the significance of the scores across the different residential zones (Table 2).

\section{RESULTS AND DISCUSSION}

The majority $(64.4 \%)$ of the respondents from the three residential zones of the city were relatively satisfied with the level of day-lighting in their houses (Table 2). The highest proportion $(78.3 \%)$ of residents who were either satisfied or very satisfied with their day-lighting level was in the medium density zone. These were the Brazilian, barrack houses with outer array of windows (Figure 2ii). The low density residents recorded the second highest (73.2\%) level of satisfaction (Table 2).

This result could not have been different, considering the morphology and window arrangement in the doublebanking face-me-l-face you rooms. Every room has adequate-sized windows at their outer walls that provide adequate lighting to each room. The central hall/passage is often opened at both ends (anterior and posterior 
Table 1. Sampling parameters for the interview.

\begin{tabular}{lcccccccc}
\hline & \multicolumn{8}{c}{ Residential zones } \\
\cline { 2 - 9 } Sample element & \multicolumn{2}{c}{ High } & \multicolumn{2}{c}{ Medium } & \multicolumn{2}{c}{ Low } & \multicolumn{2}{c}{ Total } \\
\cline { 2 - 9 } & Number & $\%$ & Number & $\%$ & Number & $\%$ & Number & $\%$ \\
\hline Streets & 35 & 40.69 & 26 & 30.23 & 25 & 29.07 & 86 & 100 \\
Houses/households & 508 & 40.74 & 377 & 30.23 & 362 & 29.03 & 1247 & 100 \\
\hline
\end{tabular}

Source: Coined from Atolagbe (2011a).

Table 2. Residents' satisfaction level with natural lighting.

\begin{tabular}{|c|c|c|c|c|c|c|c|c|c|c|}
\hline \multirow{3}{*}{ Category } & \multicolumn{8}{|c|}{ Residential density type } & \multirow{3}{*}{$\begin{array}{l}X^{2} \\
\text { value }\end{array}$} & \multirow{3}{*}{$\begin{array}{l}\text { P- } \\
\text { value }\end{array}$} \\
\hline & \multicolumn{2}{|c|}{ High } & \multicolumn{2}{|c|}{ Medium } & \multicolumn{2}{|c|}{ Low } & \multicolumn{2}{|c|}{ Total } & & \\
\hline & Number & $\%$ & Number & $\%$ & Number & $\%$ & Number & $\%$ & & \\
\hline No response & 4 & 0.8 & 1 & 0.3 & 3 & 0.8 & 8.0 & 0.6 & 125.589 & 0.001 \\
\hline Very satisfactory & 18 & 3.5 & 29 & 7.7 & 45 & 12.4 & 92 & 7.4 & & \\
\hline Satisfactory & 225 & 44.3 & 266 & 70.6 & 220 & 60.8 & 711 & 57.0 & & \\
\hline Cannot decide & 43 & 8.5 & 10 & 2.7 & 27 & 7.5 & 80 & 6.4 & & \\
\hline Unsatisfactory & 186 & 36.6 & 61 & 16.2 & 57 & 15.7 & 304 & 24.4 & & \\
\hline Very unsatisfactory & 32 & 6.3 & 10 & 2.7 & 10 & 2.8 & 52 & 4.2 & & \\
\hline Total & 508 & 100 & 377 & 100 & 362 & 100 & 1247 & 100 & & \\
\hline
\end{tabular}

Source: Author's Computation (2011).

entrances), with doors leading from the outer and inner courtyards, respectively (Figure 2ii). Only the dwarf one of the two doors (one full and the other dwarf) at each of these main entrances is closed in the afternoons, to prevent stray domestic animals and provide enough lighting for the long corridor/hall from the anterior forecourt and the posterior inner courtyard. Both dwarf and full doors are often closed in the night for security reasons. The apartments in the low density residential zone of the city, often, have relatively large windows, a multiple of $500 \mathrm{~mm}$ or $600 \mathrm{~mm}$ in width, which should add up to $15-20 \%$ of the floor area (Figure 2 iii). The compliance with this statutory requirement for plan approval, by the development control agencies of Nigeria, to achieve natural lighting and ventilation in buildings, is examined in tables.

Residents, in the high residential density zone of the city are the least satisfied with the level of their natural lighting; with 36.6 and $6.3 \%$ retuning 'unsatisfactory' and 'very unsatisfactory' opinions, respectively (Table 2).

The low satisfaction level of day-lighting in the indigenous, high-density, residential compound, housestead can be explained on the basis of the fewer, smaller windows in the houses in this zone (Table 3). These are buildings put up in the pre-colonial era, when no statutory development control machineries were in place. Every owner built to his taste, based on no public building codes or regulations at the time. Houses were built, then, to achieve a different set of socio-cultural objectives. For instance, relatively dark rooms and halls in these buildings served as aid to security in the house as there were no physical burglary proofing devices then. The dark rooms and halls provided a black body, vantage point to see advancing intruders, without residents themselves being seen. By their small sizes, less than 600 (w) X 600 (h) windows served as anti-burglary devices that would not permit burglars, aggressors or other foreign, mischievous individuals from gaining entrance into the compounds. The small, unsecured entrances could then be fortified with indigenous security tools like 'subsire' (fall-for-me-l-fall-for- you joke), 'gbalemo' (sweep the environment clean) often effected with potent charms; like a hanging bunch of brooms, tabs, knots and other potent ethno-medical devices often concealed around, or buried at the threshold of the main entrance to the house (Atolagbe, 2011a).

Other factors may also tilt the perception balance. For instance, reflectivity and refractive indices of materials and fabrics of the house may influence residents' perception, cumulating in the overall level of satisfaction of residents with day lighting.

Probably, a more important influencing factor that may exacerbate the perception of residents in the medium density zone is lighting achieved in the halls from the two open ends of the central corridor/halls; and lighting from the windows into the bedrooms. Day-lighting in the barrack houses may thus be more intensive than in the low density zone.

Figures in Table 3 show the sizes of windows in the three zones of the city in relation to the "standard size"; 
Table 3. Window sizes for lighting across the city.

\begin{tabular}{|c|c|c|c|c|c|c|c|c|c|c|c|}
\hline \multirow{3}{*}{ Variable } & \multirow{3}{*}{ Category } & \multicolumn{8}{|c|}{ Residential density type } & \multirow{3}{*}{$\begin{array}{c}\text { Critical } \\
\text { value }\end{array}$} & \multirow{3}{*}{$\begin{array}{l}\text { Sig. } \\
\text { value }\end{array}$} \\
\hline & & \multicolumn{2}{|c|}{ High } & \multicolumn{2}{|c|}{ Medium } & \multicolumn{2}{|c|}{ Low } & \multicolumn{2}{|c|}{ Total } & & \\
\hline & & Number & $\%$ & Number & $\%$ & Number & $\%$ & Number & $\%$ & & \\
\hline & No response & 17 & 3.3 & 22 & 5.8 & 7 & 1.9 & 46 & 3.7 & & \\
\hline & $\begin{array}{l}\text { All windows in living and } \\
\text { all bedrooms satisfy } 15- \\
20 \% \text { of floor space. }\end{array}$ & 7 & 1.4 & 67 & 17.8 & 210 & 57.9 & 184 & 22.6 & 29.588 & 0.000 \\
\hline & $\begin{array}{l}61-80 \% \text { of living and } \\
\text { bedrooms windows satisfy } \\
15-20 \% \text { of floor space. }\end{array}$ & 38 & 7.5 & 63 & 16.7 & 76 & 20.9 & 177 & 4.2 & & \\
\hline \multirow[t]{4}{*}{$\begin{array}{l}\text { Window sizes for lighting in } \\
\text { relation to floor space. } \\
\text { (Standard size is } 15-20 \% \text { of } \\
\text { floor area). }\end{array}$} & $\begin{array}{l}41-60 \% \text { of windows in } \\
\text { living and BRs satisfy } 15- \\
20 \% \text { of floor area. }\end{array}$ & 96 & 18.9 & 107 & 28.4 & 49 & 13.5 & 252 & 20.2 & & \\
\hline & $\begin{array}{l}\text { Only } 21-40 \% \text { of windows } \\
\text { in living and BRs satisfy } \\
15-20 \% \text { floor area. }\end{array}$ & 93 & 18.3 & 46 & 12.2 & 11 & 3.0 & 150 & 12.0 & & \\
\hline & $\begin{array}{l}\text { Only } 10-20 \% \text { living and all } \\
\text { BRs satisfy } 15-20 \% \text { of } \\
\text { floor area. }\end{array}$ & 257 & 50.6 & 72 & 19.1 & 10 & 2.8 & 239 & 4.2 & & \\
\hline & Total & 508 & 100 & 377 & 100 & 362 & 100 & 1247 & 100 & & \\
\hline
\end{tabular}

Source: Author's Computation (2011).

that is, the window size whose surface area is not less than $15 \%$ of the floor area of the room where it is used. About 58\% (57.9) of the windows in the low density residential zone have all windows (in living and bedrooms) satisfying optimum lighting condition; constituting not less than $15 \%$ of the floor area of the spaces. This is followed significantly, but distantly by the medium (17.8\%) and high (1.4\%). In all, over $90 \%$ of windows in the low density residential zone comply with the standard. This is followed by about $63 \%$ in the medium and $28 \%$ in the high density residential zones of the city. The result, with a Chi-square of 593.400, and probability value of 0.000 is significant at $99 \%$ level of confidence.

The results from Tables 2 and 3 present a clear contradiction. From the perception of users, lighting level is most satisfactory in medium density (settlement in the colonial period), than the low (post independent settlement part of the city); and least in the high (precolonial parts). But from source of day lighting - use of standard sized windows, the post-independent, low density residential zone has better lighting than other zones.

Here lies the reality in the use of users' perception. Despite better standard-sized windows in the postindependent part of the city, residents in the colonial part have better perception of day-lighting; in spite of their relatively smaller windows. The explanation to this is the additional lighting coming from the entrances at both ends of the central hall in the barrack houses.

\section{CONCLUSION AND RECOMMENDATIONS}

Day-lighting, with highest users' satisfaction of above $78 \%$, is recorded in house forms in the medium density residential zone of Ogbomoso. This is due to first, effective lighting of the double-banking corridor through the two opposite entrances - anterior and posterior - from the forecourt and courtyard/kitchen ends of the building. All bed rooms are also satisfactorily day-lighted from the array of windows at the outside walls of the rooms; with window openings ranging from (1.8 to 2.7$) \mathrm{m}^{2}$ per room. Rooms serving as living spaces in these houses are also, often longer and imbued with windows on two adjacent walls for more effective day-lighting (Figure 2ii).

Natural lighting is also satisfactory to over $73 \%$ of the residents in the mostly, single-family houses, in the low density residential zone of the city; where similar largesize windows are purposely designed to fulfill statutory lighting and ventilation requirements for building development approval. Day-lighting levels in both house forms are at comfortable levels of satisfaction to users.

It is however unsatisfactory to users in the indigenous housestead in the high density residential core of the city. In spite of the additional lighting advantages offered by the inner courtyards characterizing these house forms, windows, doorways and other openings in them are not only too few, but also too small, compared to those obtainable in other zones of the city. There is thus, much room for improvement for better day-lighting in these houses. Consequent upon the forgoing findings and 
conclusions, recommendations for better day-lighting in the Yoruba indigenous house forms are put forward at two periods in the running-life of such buildings. These are first, for improving on day-lighting in existing buildings; and second, for incorporating day-lighting in the design and approval of new buildings of this type.

\section{Day-lighting improvement on existing houses}

The greatest design and construction obstacles to installation of adequately sized openings, doors and windows in existing indigenous earth buildings are that of structure. Mud walls, though good in compression, are weak in tension. Thus, sizeable window and door openings require horizontal materials like beams and lintels, with high tensile strength, to support or transfer loads on openings to surrounding walls. Such lintel and beam materials for adequate spanning of window and door openings were not traditionally popular; nor emphasized in Yoruba indigenous mud houses. At best, they existed as short lengths of bamboo, or stakes arranged as lintels across openings; to carry the weight of earth over such openings. Any attempt to increase the span of an existing window opening would essentially involve breaking of hardened earth-walls in order to place the structural elements. This is hardly practicable without risking the collapse of the entire structure. Luckily, this housing archetype is fast disappearing in the cities in preference for modern nuclear family houses.

\section{New buildings}

A survey of house forms in the high, medium and low residential density zones of Ogbomoso shows that compound housesteads, the popular house forms among residents in the cores of Yoruba cities are gradually disappearing. Single and Brazilian house forms in the high and medium density residential zones of the cities are, however, gradually re-emerging in the low density residential zones (Atolagbe, 2011b). Some of these houses are still built with similar, local materials. These, like other buildings in this zone are, however, now subjected to statutory approval requirements by the building development control agencies. Essentially, these include design provision incorporating window sizes for adequate ventilation and lighting; and specific set-backs in houses for adequate interstitial spaces, etc. Where indigenous compound houses are required to replace aging, dilapidated ones in the high residential density zones, they should also be subjected to similar design and approval requirements.

\section{REFERENCES}

Afon AO (2006). The Use of Residents' Satisfaction Index in Selective Rehabilitation of Urban Core Residential Areas in Developing Countries. Int. Rev. Environ. Strateg. 6(1):137-152.

Agarwal A (1981). "Mud, Mud, the Potential of Earth-Based Materials for Third World Housing" Earthscan, Washington D.C.

Akinmusuru JO (1985). "Effects of Wood Reinforcement on the Building Strength of Mud Walls" Studies in Environmental Design in West Africa (5):1-5.

Atolagbe AMO (1995). "The Efficacy of Enlightenment campaign on the Acceptability of Local Materials for Affordable Housing in Nigeria: A test Case in Ogbomoso", Cultural Expression. J. Nig. Cult. Stud. $1(1): 79-85$.

Atolagbe AMO (2011a). "Security Consciousness in Indigenous Nigerian Houses: A Preliminary Survey of Yoruba Ethno-medical Devices". Stud. Ethnol. Med. 5(1):57-62.

Atolagbe AMO (2011b). "An Evaluation of the Spatial Dimensions of Housing Stress in Ogbomoso, Nigeria" An unpublished Ph.D Thesis Submitted to the Department of Geography and Environmental Management, University of Ilorin, llorin Nigeria.

Chukwuali CB (1992). "The Traditional Building Materials Earth: Old Materials, New Potentials" NIAJ A Journal of the Nigerian Institute of Architects 7(1):7-11.

Gana J (2011). "Stakeholders Interview" Nigerian Television Authority (NTA) $30^{\text {th }}$ August, 2.00pm.

Matazu G (2011). "Stakeholders Interview" Nigerian Television Authority (NTA) $30^{\text {th }}$ August, $2.00 \mathrm{pm}$.

Olateju B (1989). "Earth Construction Technology for Housing Development" Studies in Environmental Design in West Africa (8):9197.

Olateju B (1993). The Structural Performance of Bambusa Vulgaria Reinforced Terracrete Components in Flexture; The Professional Builders J. pp.30-39.

Olorunfemi JF (1995). "Pattern of Change in Accessibility and Interstitial Spaces in Ilorin", Environ. Issues (1):106-177. 